\title{
Reaction of Several Aminopyrimidines With Formaldehyde
}

\author{
Gerald L. McLeod ${ }^{1}$
}

(August 29, 1961)

\begin{abstract}
Formaldehyde has been shown to react with 2-aminopyrimidine (II) and 2-(methylamino)pyrimidine (V) at room temperature to give the corresponding methylol derivatives or the corresponding methylenebis(aminopyrimidines). The reaction of formaldehyde with 2-amino-4,6-dichloro-5-methylpyrimidine (VII) and also its failure to react with 2-(dimethylamino)pyrimidine (IX) are cited as evidence that the pyrimidine ring is not involved in the reaction.
\end{abstract}

\section{Introduction}

A number of investigations have been made on the melamine-formaldehyde reaction, and several mechanisms $[1-5]^{2}$ have been suggested. The complex structures of the triamino-1,3,5-triazines made it desirable to study simpler model compounds. A logical model compound, 2-amino-1,3,5-triazine (Ia), has been reported [6-8] not to give the usual amine reactions because it tautomerizes to the iminoid structure (Ib). Addition of more amino groups to

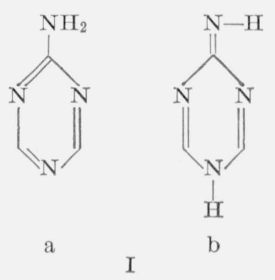

the triazine ring shifts the equilibrium to the benzenoid structure [8], thereby increasing the tendency to give amine reactions.

In the present study, it was found that 2-amino1,3,5-triazine does not react with formaldehyde under the conditions used. The 2-aminopyrimidines, which show a structural similarity to the aminotriazines, give many typical amine reactions and were selected as model compounds.

\section{Results and Discussion}

The reaction between equimolar amounts of 2-aminopyrimidine (II) and formaldehyde in neutral or slightly alkaline media at room temperature gave $N$-(2-pyrimidinyl)aminomethanol (III). The $N$ -

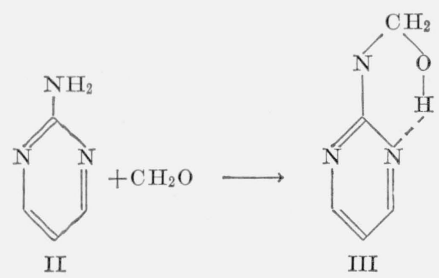

1 Present address: Itek Laboratories, Inc, Lexington 73, Mass,

2 Figures in brackets indicate the literature references at the end of this paper. methylol structure is supported by infrared analysis. The spectrum of 2-aminopyrimidine has two absorption bands near 3,320 and $3,170 \mathrm{~cm}^{-1}$ which are attributed to $\mathrm{N}-\mathrm{H}$ asymmetric and symmetric stretching modes [9]; the methylol compound, III, shows one fairly broad band at $3,225 \mathrm{~cm}^{-1}$. The occurrence of both inter- and intra-molecular hydrogen bonding in III could cause a lowering of the $\mathrm{OH}$ stretching frequency, allowing it to overlap the $\mathrm{N}-\mathrm{H}$ stretching band. Treatment of the methylol III with boiling, dilute hydrochloric acid gave $2,2^{\prime}$ (methylenediimino)dipyrimidine (IV). This com-

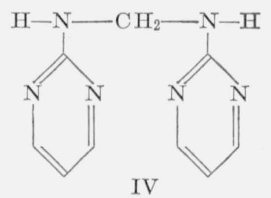

pound was also prepared from 2-aminopyrimidine (II) and half a molar equivalent of formaldehyde, using a procedure similar to one previously reported [10]. Compound IV was also prepared by the reaction of 2-aminopyrimidine (II) with the methylol III.

The compound 2-(methylamino)pyrimidine (V) was also found to give a methylol derivative on reaction with formaldehyde. This methylol derivative of $\mathrm{V}$ was less stable than the methylol deriva-
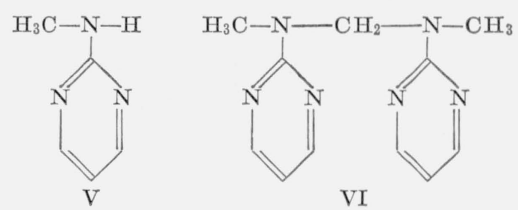

tive III and was not obtained in a pure form. It did, however, react with 2-(methylamino)pyrimidine (V) to give $2,2^{\prime}$-methylenebis (methylimino)dipyrimidine (VI), which was also formed when $\dot{V}$ was reacted with half a molar equivalent of formaldehyde. In contrast with the methylol III, treatment of the methylol compound of $\mathrm{V}$ with dilute hydrochloric acid did not give the corresponding methylenebis derivative VI. 
The following evidence indicates that formaldehyde reacts exclusively with the amino group and not with the pyrimidine ring. If formaldehyde reacted with the carbon atoms of II or V, the amino groups would be unchanged. This postulate is not in accord with the observed change in the infrared spectra. As mentioned previously, the two bands representing $\mathrm{N}-\mathrm{H}$ stretching in II are transformed into a single broad band between the two when reacted with formaldehyde. Similarly, 2-(methylamino)pyrimidine $(\mathrm{V})$, which shows a single $\mathrm{N}-\mathrm{H}$ stretching vibration near $3,250 \mathrm{~cm}^{-1}$, gives, on reaction with formaldehyde, a product showing no $\mathrm{N}-\mathrm{H}$ stretching bands. Furthermore, an aminopyrimidine with the ring-carbon atoms blocked was found to react with formaldehyde. 2-Amino-4,6dichloro-5-methylpyrimidine (VII) gave 2-2'(methylenediimino) bis (4,6-dichloro-5-methylpyrimidine) (VIII). The infrared spectrum of VII shows, as expected, two, $\mathrm{N}-\mathrm{H}$ stretching bands near 3,460 and $3,340 \mathrm{~cm}^{-1}$, whereas
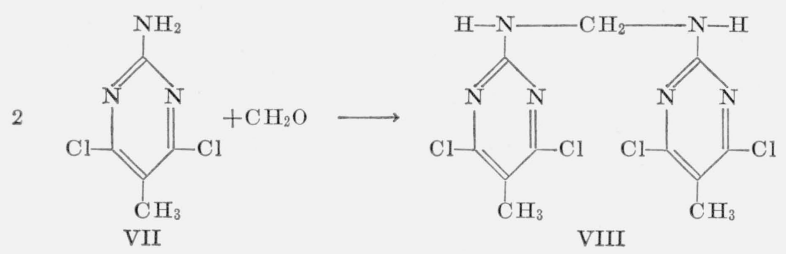

that of the methylenebispyrimidine VIII shows only one $\mathrm{N}-\mathrm{H}$ absorption band near $3,300 \mathrm{~cm}^{-1}$.

A compound with the amino group blocked, 2(dimethylamino)pyrimidine (IX), was recovered

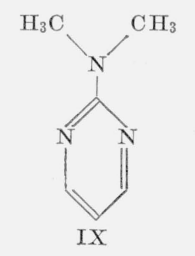

unchanged after attempts to react it with aqueous formaldehyde. The failure to react demonstrates the reluctance of the pyrimidine-ring carbon atoms to react with formaldehyde under the conditions used.

The potential ability of 2-aminopyrimidine (II) to exist to a slight extent in the imine form $[9,11]$ suggests the possibility that the reaction product with formaldehyde might have structure $\mathrm{X}$ and that the product from the reaction with 2-(methylamino)pyrimidine $(\mathrm{V})$

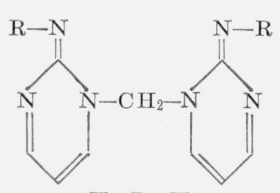

$\begin{array}{ll}\mathrm{X}, & \mathrm{R}=\mathrm{H} \\ \mathrm{XI} & \mathrm{R}=\mathrm{C} \mathrm{H}_{3}\end{array}$

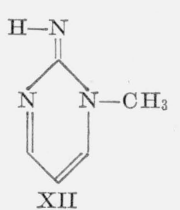

XII might be XI. The infrared spectra of all the pyrimi- dines studied in the present investigation show an absorption band of medium intensity in the region near $800 \mathrm{~cm}^{-1}$. This band is consistent with data observed elsewhere [12] and has been assigned to pyrimidine-ring vibration. Examination of the infrared spectrum of 1,2-dihydro-2-imino-1-methylpyrimidine (XII), which can be prepared from 2-aminopyrimidine (II) and methyl iodide, reveals that there is no band near $800 \mathrm{~cm}^{-1}$. This observation might be explained by the fact that the benzenoid type of resonance present in the other pyrimidine rings cannot exist in the imine XII. The structural similarity of the imine XII to structures X and XI can readily be seen. Consequently, it might be expected that compounds with imine structures $\mathrm{X}$ and XI would not show a pyrimidine-ring vibration band near $800 \mathrm{~cm}^{-1}$. In fact, the infrared spectra of the products actually obtained from the reaction of 2-aminopyrimidine (II) and 2-(methylamino)pyrimidine (V) with formaldehyde reveal the presence of the ring absorption-bands at 800 and $795 \mathrm{~cm}^{-1}$, respectively. These bands further support the assignment of structures IV and VI to these compounds.

1,2-Dihydro-2-imino-1-methypyrimidine (XII) has been described [9] as a yellow compound. This fact was confirmed in the present investigation, and it suggested that compounds having the iminoid structures $\mathrm{X}$ and XI would also be colored. By contrast, $2,2^{\prime}$-(methylenediimino)dipyrimidine (IV) and 2,2'[methylenebis(methylimino)] dipyrimidine (VI) are found to be, not colored, but white, crystalline compounds similar to the parent compounds 2-aminopyrimidine (II) and 2-(methylamino)pyrimidine (V).

This correlation of the absence of color, the presence of an absorption band in the $800 \mathrm{~cm}^{-1}$ region, and the benzenoid type of resonance is supported by the following facts. The hydriodide salt (XIII) of

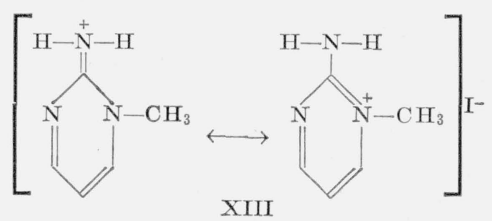

the yellow compound 1,2-dihydro-2-imino-1-methylpyrimidine (XII) is a white compound. The pyrimidine ring of the salt can have the benzenoid type of resonance and its infrared spectrum does show an absorption band at $795 \mathrm{~cm}^{-1}$.

\section{Conclusions}

On the basis of the observed data, 2-aminopyrimidine (II) and 2-(methylamino)pyrimidine (V) react with neutral aqueous formaldehyde in equimolar proportions to give the corresponding methylol compounds; reaction with half-molar proportions of formaldehyde gives the corresponding methyleneiminodipyrimidines. The reaction of the aminopyrimidines with the methylol derivatives to give the substituted iminodipyrimidines suggests the possibility that the methylol derivatives are intermediates in the direct preparation of the methyleneimino- 
dipyrimidines from the corresponding aminopyrimdines. There is no evidence of involvement of the pyrimidine ring in any of the reactions investigated.

The two $N$-methylolpyrimidines, as well as $2,2^{\prime}$-[methylenebis (methylimino)] dipyrimidine and 2,2' -(methylenediimino)bis (4,6-dichloro-5-methylpyrimidine) (VIII), are previously unreported compounds.

\section{Experimental Procedures}

Infrared analyses were made, on samples prepared as mineral-oil mulls or potassium bromide pellets, with a double-beam recording spectrophotometer (sodium chloride optics). All melting points were corrected.

2-Aminopyrimidine (II). Commercial material was recrystallized once from benzene, giving white crystals, mp 126 to $127.5^{\circ}$ (Lit. [13] 127 to $128^{\circ}$ ). Infrared analysis showed two absorption bands near 3,320 and $3,170 \mathrm{~cm}^{-1}$ due to $\mathrm{N}-\mathrm{H}$ stretching vibrations, bands at 1,650 and $1,570 \mathrm{~cm}^{-1}$ due to $\mathrm{N}-\mathrm{H}$ deformation and aromatic ring-double bond interaction $[9,12]$, and a band near $800 \mathrm{~cm}^{-1}$ probably due to pyrimidine ring vibration [12].

Reaction of 2-aminopyrimidine (II) with formaldehyde.-The preparation of $N$-(2-pyrimidinyl)aminomethanol $(I I I)$. A 37 percent aqueous solution of formaldehyde $(9.7 \mathrm{~g}, 0.12$ mole) was adjusted to a $p \mathrm{H}$ of 7-8 with several drops of 5 percent sodium hydroxide. To this solution, $11.4 \mathrm{~g}(0.12 \mathrm{~mole})$ of 2-aminopyrimidine was added, with stirring, in small portions over a period of $10 \mathrm{~min}$. The 2 -aminopyrimidine dissolved during the addition. After approximately $20 \mathrm{~min}$ of continuous stirring at room temperature, a white, solid mass formed. After several hours of cooling in an icebox, the solid was collected by suction filtration, air dried, and recrystallized from $50 \mathrm{ml}$ of dioxane in the following manner. A flask containing the product and dioxane was immersed in a water bath at 50 to $60^{\circ}$, the mixture was stirred until all solid had dissolved, and the warm solution was filtered. The clear filtrate was cooled slowly to room temperature and then cooled in an icebox for $24 \mathrm{hr}$. The white crystalline solid was collected by suction filtration, washed with a small amount of cold ethanol, and stored in a desiccator over calcium chloride for three days. The yield was $10.0 \mathrm{~g}$ (67 percent), mp 110 to $112^{\circ}$. The melting point, which was quite sensitive to the heating rate, was taken in a bath preheated to $100^{\circ}$.

Infrared analysis showed a band near $3,225 \mathrm{~cm}^{-1}$ which is probably a combination of $\mathrm{N}-\mathrm{H}$ and $\mathrm{O}-\mathrm{H}$ stretching vibrations. Four bands between 1,250 and $1,000 \mathrm{~cm}^{-1}$ (which are absent from the spectrum of 2-aminopyrimidine), including a relatively intense band at $1,018 \mathrm{~cm}^{-1}$, are probably due to $\mathrm{C}$ - O stretching or $\mathrm{OH}$ deformation [14]. A band at $800 \mathrm{~cm}^{-1}$ is probably due to pyrimidine-ring vibration.

The product was identified as $N$-(2 pyrimidinyl)aminomethanol (III) on the basis of the following analysis.

Anal. Calcd. for $\mathrm{C}_{5} \mathrm{H}_{7} \mathrm{~N}_{3} \mathrm{O}: \mathrm{C}, 47.99 ; \mathrm{H}, 5.65$; $\mathrm{N}, 33.58 ; \mathrm{O}, 12.78$. Found: $\mathrm{C}, 47.94 ; \mathrm{H}, 5.66 ; \mathrm{N}$, $33.91 ; \mathrm{O}, 13.09$.
Reaction of N-(2-pyrimidinyl)aminomethanol (III) with hydrochloric acid. A solution containing $6.25 \mathrm{~g}$ $(0.050$ mole $)$ of methylol III and $150 \mathrm{ml}$ of $0.05 \mathrm{~N}$ hydrochloric acid in a $250-\mathrm{ml}$ flask was refluxed for $5 \mathrm{hrs}$ and cooled to room temperature. The $p \mathrm{H}$ was adjusted to 8-9 with 5 percent sodium hydroxide. A white precipitate formed and the reaction mixture was cooled for three days in an icebox. The white solid was collected by suction filtration and air dried. This material slowly decomposed without melting above $350^{\circ}$ and was not investigated further.

The filtrate was neutralized with dilute hydrochloric acid and evaporated to dryness. The white residue was extracted with four $25-\mathrm{ml}$ portions of boiling ethanol. The combined extracts were evaporated to dryness and the residue, which contained sodium chloride, was extracted with a few milliliters of cold water. The remainder of the residue was recrystallized twice from ethanol, once from chloroform, and again from ethanol, giving large white needles, mp 187 to $188^{\circ}$. The product, $2,2^{\prime}$-(methylenediimino)dipyrimidine (IV) showed no melting point lowering $\left(187\right.$ to $\left.188^{\circ}\right)$ when mixed with the dipyrimidine prepared directly from 2-aminopyrimidine and formaldehyde. The infrared spectra of the two samples were identical. The spectra show a band at $3,220 \mathrm{~cm}^{-1}$ due to $\mathrm{N}-\mathrm{H}$ stretching and a band at $800 \mathrm{~cm}^{-1}$ due to pyrimidine-ring vibration. The purified product had the following analysis:

Anal. Calcd. for $\mathrm{C}_{9} \mathrm{H}_{10} \mathrm{~N}_{6}: \mathrm{C}, 53.45 ; \mathrm{H}, 4.99 ; \mathrm{N}$, 41.56. Found: C, 53.63; H, 5.15; N, 41.70 .

Attempts to prepare the picrate of $2,2^{\prime}$-(methylenediimino)dipyrimidine (IV) gave a product whose analysis and melting point agreed with those for the picrate of 2-aminopyrimidine. Apparently, hydrolysis occurred during the preparation. The picrate, prepared by the method of Shriner et al. [15], and recrystallized from 95 percent ethyl alcohol, melted at 237 to $238^{\circ}$ (Lit. [13] 237 to $238^{\circ}$ ). A mixed melting point with authentic 2-aminopyrimidine picrate showed no depression (237 to $238^{\circ}$ ).

Anal. Calcd. for $\mathrm{C}_{10} \mathrm{H}_{8} \mathrm{~N}_{6} \mathrm{O}_{7}: \mathrm{C}, 37.04 ; \mathrm{H}, 2.49$. Found: C, 36.8; H, 2.7.

Reaction of 2-aminopyrimidine (II) with formaldehyde.-Preparation of 2,2'-(methylenediimino)dipyrimidine $(I V)$. This procedure is similar to one previously reported [10], but, because of several differences, details are given. Over a 5-min period, 2.0 $\mathrm{g}$ ( $0.025 \mathrm{~mole})$ of 37 percent aqueous formaldehyde was added dropwise with stirring to a solution of $4.8 \mathrm{~g}$ ( 0.050 mole) of 2 -aminopyrimidine in $20 \mathrm{ml}$ of water. The stirring was continued for $1 \mathrm{hr}$, after which a white precipitate began forming. The reaction mixture was cooled for $4 \mathrm{hr}$ in an icebox and the solid was collected by suction filtration. Successive concentrations gave more solid. The combined crude product, mp 176 to $181^{\circ}$, was recrystallized twice from ethanol and three times from chloroform to give $2.1 \mathrm{~g}$ (42 percent) of white crystals, mp 186 to $188^{\circ}$ (Lit. [10] 180 to $182^{\circ}$ ). A mixed melting point with $2,2^{\prime}$-(methylenediimino)dipyrimidine, prepared form $N$-(2-pyrimidinyl)aminomethanol (III), showed no 
lowering (186 to $188^{\circ}$ ), and the infrared spectra of the two samples were identical.

Reaction of 2-aminopyrimidine (II) with $\mathrm{N}$-(2pyrimidinyl)aminomethanol (III). A solution of 3.13 g (0.025 mole) of $N$-(2-pyrimidinyl)aminomethanol in $15 \mathrm{ml}$ of water was added dropwise with stirring over a $10-$ min period to a solution of $2.38 \mathrm{~g}(0.025$ mole) of 2-aminopyrimidine in $15 \mathrm{ml}$ of water. The stirring was continued for an additional $90 \mathrm{~min}$. After evaporation of the solution to one-third the origina vollume and cooling for several days in an icebox, a white solid was obtained. The product was collected by suction filtration and recrystallized twice from chloroform and once from ethanol, giving $2.5 \mathrm{~g}$ of shiny, white crystals, $\mathrm{mp} 187$ to $189^{\circ}$. A mixed melting point with $2,2^{\prime}$-(methylenediimino)dipyrimidine (IV) showed no lowering (187 to $189^{\circ}$ ) and the infrared spectra of the two compounds were identical.

2-(Methylamino) pyrimidine $(V)$. This procedure is similar to that of Overberger and Kogon [16] for the preparation of the hydriodide salt and to that of Brown et al. [9], for the preparation of the free amine. The hydriodide salt was prepared from 2-aminopyrimidine and methyl iodide in 91 percent yield. ${ }^{3}$ The white crystals, after recrystallization from ethanol, melted at 242 to $244^{\circ}$ (Lit. 241 to $242^{\circ}$ [16]; 242 to $244^{\circ}$ [9]).

The hydriodide salt was converted to 2-(methylamino)pyrimidine (V) by heating in an alcoholic sodium hydroxide solution for several minutes. After recrystallization from petroleum ether (bp 30 to $60^{\circ}$ ), the white crystalline solid (yield 77 percent based on amine salt) melted at 61.5 to $62.5^{\circ}$. (Lit. 58 to $59.5^{\circ}[16] ; 59$ to $60^{\circ}[9]$ ).

The infrared spectra showed an $\mathrm{N}-\mathrm{H}$ stretching vibration near $3,250 \mathrm{~cm}^{-1}$, a band near $1,610 \mathrm{~cm}^{-1}$ probably due to ring double-bond stretching [9], and the pyrimidine-ring stretching-vibration at 800 $\mathrm{cm}^{-1}$.

The picrate, prepared by the procedure of Shriner et al. [15], gave, on recrystallization from 95 percent ethyl alcohol, yellow needles, mp 194 to $195^{\circ}$ (Lit. 195 to $\left.196^{\circ}[16] ; 191^{\circ}[9]\right)$.

Reaction of 2-(methylamino)pyrimidine $(V)$ with formaldehyde.-Preparation of the methylol derivative. A mixture of $3.3 \mathrm{~g}$ (0.030 mole) of 2-(methylamino)pyrimidine and $2.4 \mathrm{~g}$ (0.030 mole) of 37 percent aqueous formaldehyde solution was stirred in a small flask at room temperature for $1 \mathrm{hr}$. All of the solid dissolved in approximately $5 \mathrm{~min}$. The reaction mixture was cooled for three days in an icebox and the white solid collected by suction filtration. The yield of product was $2.6 \mathrm{~g}$ (62 percent), mp 61 to $62^{\circ}$. An additional amount of white crystalline product $(0.63 \mathrm{~g}), \mathrm{mp} 60$ to $62.5^{\circ}$, was isolated from the mother liquor. This methylol compound was unstable and was not further purified. It also gave poor and inconsistent analyses. On admixture with 2-(methylamino) pyrimidine, a noticeable softening or partial melting occurred at room temperature.

\footnotetext{
3 Brown and coworkers [9] suggested that the alkylation of 2-aminopyrimidine with methyl iodide actually gives the hydriodide of 1,2-dihydro-2-imino-1methylpyrimidine (XIII), which rearranges to 2-(methylamino)pyrimidine (V) on treatment with warm, alkaline solution.
}

Reaction of 2-(methylamino)pyrimidine ( $V)$ with formaldehyde.-The preparation of 2,2'-methylenebis(methylimino) dipyrimidine (VI). A 37 percent aqueous solution of formaldehyde ( $1.0 \mathrm{~g}, 0.012 \mathrm{~mole})$ was added dropwise with stirring over a period of several minutes to $2.75 \mathrm{~g}$ (0.025 mole) of 2-(methylamino)pyrimidine in $5 \mathrm{ml}$ of water, and stirring was continued for $30 \mathrm{~min}$. After being heated for $10 \mathrm{~min}$ on a steam bath, the solution became cloudy, and an oil separated. After ten more minutes of heating, the reaction mixture was stored in an icebox for four days, and the white solid was collected by suction filtration and air dried. Yield $2.35 \mathrm{~g}$ ( 85 percent), $\mathrm{mp} 86.5$ to $88^{\circ}$. Recrystallization from $15 \mathrm{ml}$ of petroleum ether (bp 30 to $60^{\circ}$ ) gave $2.23 \mathrm{~g}$ ( 81 percent) of long, white needles, mp 87 to $88^{\circ}$.

Infrared analysis of this product showed no N-H stretching vibration. Absorption bands near 1,590 and $1,555 \mathrm{~cm}^{-1}$ are probably due to interaction effects of ring double-bonds [12] and a band at $795 \mathrm{~cm}^{-1}$ is probably due to pyrimidine-ring vibrations.

Anal. Calcd. for $\mathrm{C}_{11} \mathrm{H}_{14} \mathrm{~N}_{6}: \mathrm{C}, 57.37 ; \mathrm{H}, 6.13 ; \mathrm{N}$, 36.50. Found: C, $57.33 ; \mathrm{H}, 6.24 ; \mathrm{N}, 36.81$.

Reaction of 2-(methylamino)pyrimidine $(V)$ with $N$-methyl-N-(2-pyrimidinyl)aminomethanol. A mix-ture of $0.41 \mathrm{~g}$ (0.0037 mole) of 2 (methylamino)pyrimidine, $0.52 \mathrm{~g}$ (0.0037 mole) of the methylol derivative, and $5 \mathrm{ml}$ of water in a small flask was stirred and warmed on a steam bath for $10 \mathrm{~min}$. All of the solid dissolved during the warming period. The clear solution was cooled to room temperature and, after standing for two days, deposited white crystals. After removal of the crystals, the filtrate, on standing two more days, deposited more solid. The total product, which, after air drying, weighed $0.7 \mathrm{~g}$ (82 percent), was recrystallized from petroleum ether (bp 30 to $60^{\circ}$ ), giving $0.65 \mathrm{~g}$ (76 percent) of white needles, mp 87 to $88^{\circ}$.

A mixed $\mathrm{mp}$ with 2,2'-methylenebis (methyleneimino) dipyrimidine (VI) prepared from 2-(methylamino)pyrimidine and formaldehyde showed no lowering $\left(87\right.$ to $88^{\circ}$ ). The infrared spectra of the two samples were identical.

2-(Dimethylamino)pyrimidine $(I X)$. The procedure used was similar to that of Overberger et al. $[16,17]$. 2-Chloropyrimidine was prepared by diazotization of 2-aminopyrimidine with sodium nitrite and hydrochloric acid. The product, after three recrystallizations from petroleum ether (bp 38 to $55^{\circ}$ ), gave white crystals (23 percent), mp 65 to $66.5^{\circ}$ (Lit [16] 64.5 to $65.5^{\circ}$ ).

2-(Dimethylamino)pyrimidine was prepared from 2-chloropyrimidine by bubbling anhydrous dimethylamine into a refluxing solution of the chloropyrimidine in absolute ethyl alcohol. The crude 2(dimethylamino)pyrimidine was distilled through a 12-cm Vigreux column, giving a colorless liquid (85 percent), bp $79-81^{\circ}(20 \mathrm{~mm}), n_{\mathrm{D}}{ }^{24} 1.5438$ (Lit. [16] 88 percent, bp $86^{\circ}(28 \mathrm{~mm}), n_{\mathrm{D}}{ }^{25} 1.5420$; Lit. [11] 46 percent, bp 78 to $\left.81^{\circ}(17 \mathrm{~mm}), n_{\mathrm{D}}{ }^{22} 1.5438\right)$.

Infrared analyses of a liquid sample show several $\mathrm{C}-\mathrm{H}$ stretching bands in the region of 3,150 to 2,800 $\mathrm{cm}^{-1}$, several bands characteristic of ring doublebond interaction effects between 1,600 and 1,400 
$\mathrm{cm}^{-1}$, and the $800 \mathrm{~cm}^{-1}$ band due to pyrimidine-ring vibration.

The picrate was prepared by adding an ethereal solution of picric acid to an ethereal solution of 2 (dimethylamino)pyrimidine. Recrystallization from ethyl alcohol gave yellow crystals, mp 173 to $175^{\circ}$ (Lit. [16] 170.5 to $171.5^{\circ}$ ).

Reaction of 2-(dimethylamino)pyrimidine $(I X)$ with formaldehyde. A mixture of $1.23 \mathrm{~g}(0.010 \mathrm{~mole})$ of 2 -(dimethylamino)pyrimidine and $0.4 \mathrm{~g}(0.005$ mole $)$ of aqueous 37 percent formaldehyde solution was stirred at room temperature for $90 \mathrm{~min}$. After an additional hour, no solid had deposited, and the reaction mixture was extracted with five $6-\mathrm{ml}$ portions of ether. A small amount of sodium chloride was added to the reaction mixture to lower the solubility of any organic material present. The combined ether extracts were dried over anhydrous magnesium sulfate for $3 \mathrm{hr}$. Removal of the ether by distillation and of the remaining residue by vacuum distillation gave $1.18 \mathrm{~g}$ of 2 -(dimethylamino)pyrimidine, bp 84 to $86^{\circ}(22 \mathrm{~mm}) n_{\mathrm{D}}{ }^{23} 1.5430$.

In another experiment, the 2-(dimethylamino)pyrimidine and formaldehyde were stirred together for $1 \mathrm{hr}$, heated on a steam bath for half an hour, and cooled for one day in an icebox. The reaction mixture, treated as previously described, gave $1.17 \mathrm{~g}$ of unchanged 2-(dimethylamino)pyrimidine. In both instances, nearly quantitative recovery of unchanged 2 -(dimethylamino)pyrimidine was obtained.

Picrates prepared from the compound recovered from these attempted reactions with formaldehyde gave no melting-point lowering (173 to $\left.175^{\circ}\right)$ when mixed with a sample of the picrate of 2-(dimethylamino)pyrimidine.

Reaction of 2-amino-4,6-dichloro-5-methylpyrimidine (VII) with formaldehyde. Portions of commercial 2-amino-4,6-dichloro-5-methylpyrimidine were purified by vacuum sublimation $\left(200^{\circ} ; 1 \mathrm{~mm}\right)$ or by recrystallization from ethyl alcohol, giving a white solid, $\mathrm{mp} 252$ to $254^{\circ}$ (Lit. [18] $249^{\circ}$ ). Sublimation was the preferable method, because of the low solubility of the chloropyrimidine.

A mixture of $0.9 \mathrm{~g}(0.05$ mole $)$ of 2 -amino- 4,6 dichloro-5-methylpyrimidine and excess $(25 \mathrm{ml})$ of 37 percent aqueous formaldehyde solution was boiled for $10 \mathrm{~min}$ and filtered while still hot, to remove undissolved starting material. Concentration of the filtrate to one-third volume, followed by cooling to room temperature, gave a white solid. Two recrystallizations from ethanol gave about 50 $\mathrm{mg}$ of a white, crystalline solid, $\mathrm{mp} 240$ to $242^{\circ}$, which is probably $2,2^{\prime}$-(methylenediimino)bis $(4,6$ dichloro-5-methylpyrimidine) (VIII), based on the following analysis.

Anal. Calcd. for $\mathrm{C}_{11} \mathrm{H}_{10} \mathrm{Cl}_{4} \mathrm{~N}_{6}: \mathrm{N}, 22.83 ; \mathrm{Cl}, 38.54$. Found: N, 22.72; Cl, 38.39.

Infrared analysis of the starting material, VII, showed two $\mathrm{N}-\mathrm{H}$ stretching bands near 3,460 and $3,440 \mathrm{~cm}^{-1}$. The reaction product, VIII, showed a single $\mathrm{N}-\mathrm{H}$ stretching band near $3,300 \mathrm{~cm}^{-1}$. Both compounds showed the absorption band near $800 \mathrm{~cm}^{-1}$ characteristic of pyrimidine-ring stretching.
1,2-Dihydro-2-imino-1-methylpyrimidine (XII). This compound was prepared from 2-aminopyrimidine and methyl iodide according to the procedure of Brown et al. [9]. The product, a yellow solid, melted at 101 to $103^{\circ}$ (Lit. [9] 102 to $104^{\circ}$ ).

Infrared analysis showed an $\mathrm{N}-\mathrm{H}$ stretching band near $3,246 \mathrm{~cm}^{-1}$, and a band near $1,646 \mathrm{~cm}^{-1}$ due to double-bond stretching [9]. There was no band near $800 \mathrm{~cm}^{-1}$ typical of pyrimidine-ring vibration.

The infrared spectrum of the hydriodide salt, XIII, showed two absorption bands near 3,400 and $3,200 \mathrm{~cm}^{-1}$ and a band near $1,650 \mathrm{~cm}^{-1}$. An absorption band at $795 \mathrm{~cm}^{-1}$ was probably due to pyrimidine-ring vibration.

2-Amino-1,3,5-triazine (I). The procedure consisted of heating a mixture of formylguanidine [19] and formamide with powdered sodium hydroxide, and was essentially that of Grundmann et al. [7]. The product, a white crystalline solid, mp 224 to $226^{\circ}$ (Lit [7] 225 to $226^{\circ}$ ) gave the following analysis.

Anal. Caled. for $\mathrm{C}_{3} \mathrm{H}_{4} \mathrm{~N}_{4}: \mathrm{C}, 37.50 ; \mathrm{H}, 4.19 ; \mathrm{N}$, 58.31. Found: C, 37.21; H, 4.21; N, 58.71.

Attempts to react 2-amino-1,3,5-triazine with formaldehyde in neutral solution were unsuccessful.

The author thanks Miss M. Kathryn Wharton and Max Tryon for assistance with the infrared analyses, and Mrs. Elli Hand for the preparation of several compounds.

\section{References}

[1] A. Gams, G. Widmer, and W. Fisch, Brit. Plastics 14, 508 (1943).

[2] H. P. Wohnsiedler, Ind. Eng. Chem. 44, 2679 (1952).

[3] H. P. Wohnsiedler, Ind. Eng. Chem. 45, 2307 (1953).

[4] H. P. Wohnsiedler, Ind. Eng. Chem. 48, 82 (1956).

[5] R. F. Goldstein, Plastics Inst. (London) Trans. 21, 18 (1953).

[6] A. Burger and E. D. Hornbaker, J. Am. Chem. Soc. 75, 4579 (1953).

[7] C. Grundmann, L. Schwennicke, and E. Beyer, Chem. Ber. 8\%, 19 (1954).

[8] L. Paolini, Gazz. chim. ital. 84, 735 (1954) [C.A. 50, $1039 i$ (1956)].

[9] D. J. Brown, E. Hoerger, and S. F. Mason, J. Chem. Soc. 1955, 4035 .

[10] B. Skowrońska-Serafinowa, Roczniki Chem. 29, 932 (1955) [C.A. 50, $6464 b$ (1956)].

[11] D. J. Brown and L. N. Short, J. Chem. Soc. 1953, 331.

[12] L. J. Bellamy, The infrared spectra of complex molecules (John Wiley \& Sons, Inc., New York, N.Y., 2d ed., 1958, 277, 283).

[13] E. Büttner, Ber. deut. chem. Ges. 36, 2229 (1903).

[14] L. J. Bellamy, The infrared spectra of complex molecules (John Wiley \& Sons, Inc., New York, N.Y., 2d ed., 1958, 108, 188).

[15] R. L. Shriner, R. C. Fuson, and D. Y. Curtin, The systematic identification of organic compounds, (John Wiley \& Sons, Inc., New York, N.Y., 4th ed., 1956, 229).

[16] C. G. Overberger and I. C. Kogon, J. Am. Chem. Soc. \% 6, 1065 (1954).

[17] C. G. Overberger, I. C. Kogon, and R. Minin, Org. Syntheses 35, 34 (1955).

[18] O. Gerngross, Ber. deut. chem. Ges. 38, 3394 (1905).

[19] W. Traube, Ber. deut. chem. Ges. 43, 3587 (1910).

(Paper 66A1-141) 